\title{
Research on the Introduction of CRM Service Management System - Case Analysis of the Car Factory
}

\author{
Chu Fang \\ Beijing Institute of Technology, Zhuhai
}

\begin{abstract}
Customer Relationship Management (CRM) refers to the way to understand and influence customer behavior through continuous communication, in order to win new customers, consolidate existing customers and increase customer profit contribution. The CRM range is wide and deep, overall planning of information integration, and the "customer management", "marketing management", "service management", "marketing management" as the core information integration, so that enterprises can provide enterprise and customer relationship management, and customer classification can help enterprises, more in-depth understanding of their customers, meet the market demand according to the customer and business style, create the enterprise core value and competitive niche. The study will use the process and procedure of CRM service management in the enterprise actual import to understand, how to import the CRM system by modern enterprises to strengthen its competitiveness, and provide the day after the intention to import this system as a reference and guide enterprises.
\end{abstract}

Keywords-Customer relationship management (CRM); Business process reengineering; Case study; System implementing

\section{INTRODUCTION}

In the customer-oriented era, customer relationship management (CRM Customer Relationship Management) importance gradually over the past everyone in the enterprise resource planning (ERP Enterprise Resource on the Planning), is mainly because the use information technology can increase the competitiveness of enterprises is an indisputable fact that the market competition is not necessary weapons update, but after everybody build ERP advantage even enterprise, so must constantly seek new weapons, to strengthen the competitiveness. Customer is the most important foundation for a company except employees, and the ultimate goal of enterprises is to extend products to customers in the market [5]. Therefore, knowing and grasping customers is the lifeblood of enterprises.

So where is the spirit of CRM? Why is the customer relationship management system? The goal of CRM is, of course, to achieve a win-win situation with the customer after the information system can maintain a good relationship with the customer [2]. So what do you do? Hope that through a system like CRM can make the company all staff and customers with this system specification [8], know how to interact with customers, and recording and sharing of information between all clients, customers will be further classified to provide differentiated services and marketing services, to achieve effective economy, customer satisfaction and increase the company's profit.

For the overall benefit, the purpose of customer relationship management (CRM) is mainly to increase the effectiveness of sales, service and marketing activities [6], so as to enhance customer loyalty and provide sustainable business opportunities for enterprises.

Text

How to strengthen competitive advantage by CRM:

Effectively tracking the trend of customer relationship

Analyze and classify customers to provide services with different priorities

* integrate customer - centered information and provide relevant department reference

* improve customer loyalty and service quality and reduce the loss rate of customers

Effective improvement of communication and operation interaction

* Clearly record customer related activities and feedback needs

Reducing the dependence on people without affecting the service level and quality of customers.

\section{CASE ANALYSIS}

We have a well-known car factory (B) to discuss the planning and customer management system. The actual import case as follows: May in fifty-eight years, B company was formally established in August of the same year became a wellknown German car Taiwan exclusive general agent, is responsible for the well-known automobile products sales and service.

Staff: nearly nine hundred people, has a total of nine companies and seven dealers in the province, and has established a thirty-two Exhibition Center and thirty service factory dense service network. Over the past three years, the 
annual turnover has exceeded NT \$eleven billion, ranking the top importing Car Dealer in Taiwan and ranking the top fifty in the three hundred service industries.

In the process of e will not be discarded and $\%$ to provide better service to customers, B companies are actively involved in CRM system planning and the stages of introduction, and the company has always been honest service, integrity management, customer-focused service concept, to achieve the same commitment to consumers. B is planning to start in the third quarter of this year

Phased introduction of a series of new management systems to gradually build a customer management system, we will introduce its import service management system to introduce and discuss.

\section{System integration}

Build a complete database and integrate sales, marketing, and services through the internal network [7]. The system, each department can provide the answers to the related information and related questions for the data they need. Through such integration, the service staff can capture the following relevant information in the scope of their authority to provide personalized service to the customers:

1) Basic data of the customer

2) Transaction history data

3) The customer's car book information

4) Car maintenance records

Sales staff can make use of the company's PDA provided by the company, using wireless internet access to the company website DOWNLOAD product information, quotation... Provide the most real-time information to the customer.

Provide customer add value

B plans to add a new set of standards for each new car, which includes:

1) Cradle +wireless communication interface for PDA + multifunction vehicle

2) Compact Flash GPS satellite positioning system

Application principle of car machine

Location of vehicle location with Compact GPS receiver and Repeater

Using HP Jornada Pocket PC as the system host

Use the HP connection seat (Cradle) to connect with the Nokia 6150

The user service is provided by adding a function button on the HP connection seat

Customer service center software receives related signals and provides services.

\section{Cradle button function:}

Call Center (the owner liaisons directly with the monitoring center)
- call the monitoring center directly by the service staff

SOS (emergency request assistance) - direct transmission of SOS signals through SMS to the monitoring center (the monitoring center will receive the current position and signal pattern of the car)

Road Service (query facility information) - call MobileMap navigation software facility query function Navi (using navigation system) -- start MobileMap navigation software

Dial (dialing) - providing the function E-mail (receiving email) to call Mobile phone -- start Pocket Outlook

The added value of this system:

1) Action office: customers can use PDA to send and receive e-mail on the car and get real time news and information on the Internet.

2) Information acquisition: we can query the nearest garage location, member activity information, latest preferential items, food and clothing, housing and entertainment information by setting up the information network set by B company. Wait。

3) Satellite navigation system: car PDA built GIS (map software), with C.F. GPS Receiver for automobile navigation.

\section{CONCLUSION}

With the rise of consumer awareness, the quality of the service is to replace the trend of price competition, because consumers will not A products ten yuan cheaper than B products and A products, the enterprise is now than on consumer one to one service, if the enterprise service can make consumers satisfied, feel comfortable, convenient, intimate, won the sales the niche, while the CRM system is designed for how to make consumers satisfied.

Conduct the study in this case, there is no actual implementation result and data due to the introduction stage. But in the era of electronic commerce and competition among industries, the introduction of CRM will be an inevitable trend. Through the discussion of the above cases, we have concluded the following conclusions and explained the results by the actual results of other companies.

\section{Choose the most suitable process}

In order to establish good relationship, enterprises must interact with customers continuously, if they can lead customers into the most suitable pipeline of business transactions [4], they will save huge cost. B builds Call Center to provide its customers with the most real-time services and electronic processes to improve service efficiency. Since there is no actual data showing the implementation of the outcome, we take the Taiwan Citibank as an example, according to statistics, the customer accept the financial services through telephone voice (phone banking), the average cost is eight yuan [3], the phone is six yuan, special treatment, if it uses the branch Commissioner when facing processing, the cost is high, up to one or two yuan. In order to drive the customer to use the telephone voice service, Citibank set up a twenty-four hour telephone financial center. Bring customers into the telephone 
center, and try to transform the financial center into a "customer relationship center".

It is worth noting that the most suitable process for enterprises is also the most suitable process for customers to be meaningful, otherwise, it will only bring harm to the relationship between enterprises and customers.

\section{Be classified}

Provide tailor-made type service for the customer, the customer relationship management is the ultimate goal. This goal may be hard to achieve, but according to the different characteristics, needs and experience of customers, it is a basic lesson to classify and classify the most appropriate services. But if there is less process of effective analysis of these data, it is likely to lose the opportunity to obtain accurate business opportunities.

In Taiwan, a mobile operator approach as an example, the company has a special line to the high amount of customers[1], they will not be met because the system is busy and unreasonable situation; in addition, the high amount of customers to call the customer service center, the phone will automatically transfer to a group of experienced service personnel. "This type of customer cares about time, so we don't let them waste too much time waiting," the industry said. On the contrary, the low consumption customers may be more concerned about the cost than the waiting time.

The information

Understanding customer experience, classifying them, and designing the most appropriate process to contact customers, these steps are based on sufficient information. In order to make the most full collection and interpretation of information, the application of science and technology is a very important part of the modern customer relationship management.

Customer Relationship Management (CRM) has been discussed many times since its definition, scope and usage. It has become a hot topic in business management today [9]. Most of the early manufacturers only for "sales automation" (Sales Force Automation), or the "customer service center" (Call Center/Service Center) of the separate management and operation, until the customer relationship management (CRM) of the whole application has received considerable attention, when manufacturers began to mergers and acquisitions, to various manufacturers of existing product segments and pieced together a complete blueprint CRM. Believe CRM, it will follow enterprise resource planning (ERP), and become an enterprise transition into electronic business (e-Business), is also a necessary condition for the success of enterprises in the new century.
Customer relationship management should include the integration of marketing, sales and service processes (Collaboration), and the enterprise external windows electronic customer service center (e Center), including traditional telephone customer service centers and websites [10].

CTI Call Center - omni-directional customer contact management.

How does a customer service center work to improve customer contact and improve business customer service? Speaking of enterprise customer service center, service process and sales process mechanism, forming a virtuous circle, with a high degree of interaction and customer-focused, and constantly develop products to meet market demand, and constantly improve the enterprise's own system, to achieve sustainable development and survival of the ideal.

Customer Relationship Management: In this phase, the integration of CTI system and back-end process of customer service center is continuously strengthened to achieve the background of the background. Sales-Force Automation (SFA) facilitates fast response to customer needs, creating orders for data mining and data warehousing systems, and deepening understanding of customer needs One-to-one marketing to One Marketing status, so that customers receive personalized service (Personal Treatment).

\section{REFERENCES}

[1] Business decision-making Forum] twenty-second, author: Dr. Su Shouqian. (In Chinese)

[2] Customer relationship management relationship management insigst / Customer depth analysis] engine management consulting company far published.

[3] Business decision Forum] twenty-second, author: Wu Zhenming, Huang Qionghui. (In Chinese)

[4] Service marketing management] the business series is published, and shelson has compiled it.

[5] Marketing management - Asian example] author: Philip Kotler / Siew Meng Leong / Swee HoonAng/Chin Tiong Tan). (In Chinese)

[6] The world magazine -- do I CRM to win customer loyalty] 224th, author: Mo Naijian. (In Chinese)

[7] Business decision Forum] twenty-fourth phase, author: Qiu Rong. (In Chinese)

[8] Http://www.sme.ctm.net digital enterprise, author: Hong Yiyan. (In Chinese).

[9] [one to one manager: e's successful customer relationship management] Don peppers; Martha Rogers, Lan Yuren, Jiang Qinghui.

[10] [Taiwan international e-commerce center -- a ramble on CRM architecture and significance] http://www.nii.org.tw, author: Deral. (In Chinese). 